\title{
A Novel Nanofibrous Film Chemosensor for Detecting and Adsorbing $\mathrm{Fe}^{3+}$
}

\author{
Chen Zhou,* Yinan Zhang and Heng Liu \\ Research Center for Nanotechnology, Changchun University of Science and Technology, \\ 130022 Changchun, P. R. China
}

\begin{abstract}
A novel nanofibrous film chemosensor was designed and fabricated for detecting $\mathrm{Fe}^{3+}$. It displayed good sensitivity and selectivity as a sensing material for $\mathrm{Fe}^{3+}$. The addition of $\mathrm{Fe}^{3+}$ would induce obvious fluorescent quenching of the nanofibrous film and the other common metal ions did not interfere in the recognition of $\mathrm{Fe}^{3+}$. The detection limit for $\mathrm{Fe}^{3+}$ of this sensing material was calculated to be $10.63 \mu \mathrm{mol} \mathrm{L}{ }^{-1}$. Moreover, the nanofibrous film could not only be regarded as a chemosensor for detecting $\mathrm{Fe}^{3+}$, but also as an adsorbent to remove $\mathrm{Fe}^{3+}$ with high efficiency in solution. The adsorption capacity was calculated to be $13.93 \mathrm{mg} \mathrm{g}^{-1} \mathrm{of} \mathrm{Fe}^{3+} /$ nanofibrous film from Langmuir plot.
\end{abstract}

Keywords: electrospinning, nanofibrous film, ferric ion, fluorescent sensor, adsorbent

\section{Introduction}

$\mathrm{Fe}^{3+}$ is one of the most essential elements in human body. As a cofactor, it plays a role in plenty of enzymatic reactions in physiological processes. Lack of $\mathrm{Fe}^{3+}$ can cause many physiological changes, leading to low immunity, mental decline, neurological disorders, reduced ability to resist infection and to regulate the body temperature, along with other symptoms. ${ }^{1,2}$ Meanwhile, excessive $\mathrm{Fe}^{3+}$ in the body will result in methemoglobinemia, which is a metabolic disease that influences oxygen blood flow. ${ }^{3}$ So it is of great significance to develop chemosensors for $\mathrm{Fe}^{3+}$ in modern society. With the development of fluorescence technology, fluorescent sensors for metal ions have received great attention in the last few decades due to their useful applications in various areas. Fluorescent nanomaterials are playing important role in environmental sciences, biology and chemistry. Indeed, enormous efforts have been devoted to the research of $\mathrm{Fe}^{3+}$ nanosensors.

Electrospinning is one of the simplest techniques for preparing nanofibrous film, which has been a currently hot topic. The film structure is endowed with high specific area and porosity, and the porous network structure can greatly improve the diffusion velocity of analytes inside nanofibrous film, which allows its interaction with the functional groups distributed along the whole film..$^{5-7}$ The above advantages make nanofibrous film very suitable for grafting fluorescent probes. So a large number of

*e-mail: zhouchen@ cust.edu.cn electrospun fibrous film chemosensors for some analytes were designed and synthetized in recent years. They have been used to detect or adsorb different kinds of substances, such as anions, metal ions or other organic compounds. ${ }^{8-11}$ So, the synthesis of a functionalized electrospun nanofibrous film for recognizing and adsorbing $\mathrm{Fe}^{3+}$ is of great importance.

\section{Experimental}

Synthesis of 7-(diethylamino)-3-formyl-coumarin ${ }^{12}$

4-(Diethylamino)-2-hydroxybenzaldehyde (1.33 g, $6.9 \mathrm{mmol})$, diethyl malonate $(1.65 \mathrm{~g}, 10.35 \mathrm{mmol})$, piperidine $(1.77 \mathrm{~g}, 20.8 \mathrm{mmol})$ and two drops of acetic acid were dissolved in $100 \mathrm{~mL}$ ethanol. The mixture was refluxed under $\mathrm{N}_{2}$ for $12 \mathrm{~h}$, then, the solvent was distilled and the crude product was purified by column chromatography, ethyl acetate:dichloromethane (EtOAc: $\mathrm{CH}_{2} \mathrm{Cl}_{2}=1: 4$, v/v) on silica gel to obtain 7-(diethylamino)-3-formyl-coumarin as a yellow oil (2.18 g, yield $75 \%) .{ }^{1} \mathrm{H}$ NMR $(300 \mathrm{MHz}$, $\left.\mathrm{CDCl}_{3}\right) \delta 1.38\left(\mathrm{~m}, 4 \mathrm{H}, \mathrm{CH}_{2}\right), 1.53\left(\mathrm{~m}, 6 \mathrm{H}, \mathrm{CH}_{3}\right), 6.82(\mathrm{~s}$, 1H, Ph-H), 6.76 (s, 1H, Ph-H), 8.50 (s, 2H, Ph-H).

Synthesis of poly (acrylonitrile-co-acroleic acid) (PANA)

Acrylonitrile $(5.9 \mathrm{~g}, 0.1 \mathrm{~mol})$, acroleic acid $(7.2 \mathrm{~g}$, $0.1 \mathrm{~mol})$ and azobisisobutyronitrile (AIBN) $(0.02 \mathrm{~g}$, $10 \mathrm{mmol}$ ) were dissolved in $10 \mathrm{~mL}$ dimethyl formamide (DMF) in a flask with three necks, then $\mathrm{N}_{2}$ was introduced 


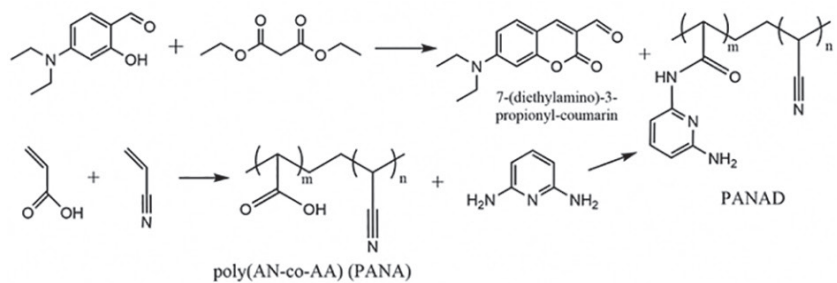

poly(AN-co-AA) (PANA)

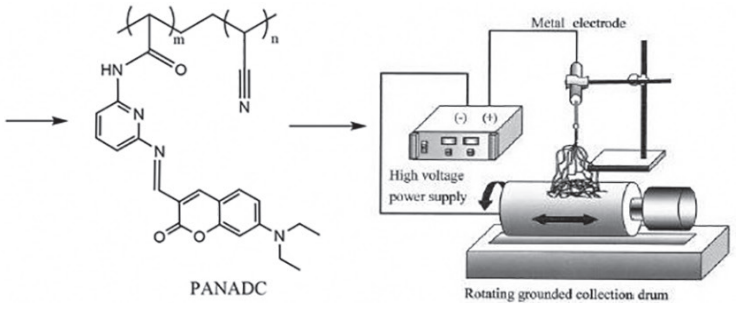

Scheme 1. Synthesis of fluorescent nanofibrous film.

into the flask for $5 \mathrm{~min}$ to remove $\mathrm{O}_{2}$ and the bottle was sealed under $70{ }^{\circ} \mathrm{C}$ for $24 \mathrm{~h}$. After that, yellow viscous polymer was generated, the crude product was washed with methanol for 3 times to obtain almost transparent viscous polymer, which was dried under vacuum at $50{ }^{\circ} \mathrm{C}$ for $24 \mathrm{~h}$ to remove the residual methanol.

Synthesis of poly (acrylonitrile-co-acroleic acid-co-diaminopyridine) (PANAD)

PANA (2.6 g), 2,6-diaminopyridine (4.4 g, $40 \mathrm{mmol}$ ) and 1-(3-dimethylaminopropyl)-3-ethylcarbondiimide hydrochloride (EDC) $(0.1 \mathrm{~g})$ were dissolved in $25 \mathrm{~mL}$ DMF, heated to $110^{\circ} \mathrm{C}$ for $12 \mathrm{~h}$. DMF was removed by vaccum distillation and the crude product was washed with methanol for 4 times to obtain brown viscous polymer, which was dried under vacuum at $50{ }^{\circ} \mathrm{C}$ for $24 \mathrm{~h}$ to remove the residual methanol, then $3.6 \mathrm{~g}$ PANAD was collected (yield 40\%). ${ }^{1} \mathrm{H}$ NMR (300 MHz, $\left.\mathrm{CDCl}_{3}\right) \delta 1.24(\mathrm{~m}, \mathrm{H}$, $\mathrm{CH}), 2.89$ (m, 2H, $\left.\mathrm{CH}_{2}\right), 3.31$ (m, H, CH), 3.94 (m, 2H, $\mathrm{CH}_{2}$ ), 6.96 (m, H, Ph-H), 7.01 (m, H, Ph-H), 7.60 (m, H, Ph-H), 7.71 (d, H, J 3.3 Hz, Ph-H), 10.69 (s, H, NH).

\section{Synthesis of poly (acrylonitrile-co-acroleic acid-co-diamino- pyridine-co-coumarin) (PANADC)}

PANAD (2.0 g), and 7-(diethylamino)-3-formylcoumarin $(3.86 \mathrm{~g}, 20 \mathrm{mmol})$ were dissolved in $40 \mathrm{~mL} \mathrm{DMF}$. The mixture was heated to $80^{\circ} \mathrm{C}$ for $8 \mathrm{~h}$, the crude product was washed with methanol 4 times to obtain PANADC as a yellow viscous polymer. ${ }^{1} \mathrm{H} \mathrm{NMR}\left(300 \mathrm{MHz}, \mathrm{CDCl}_{3}\right) \delta 0.63$ (m, H, CH), 0.94 (s, 2H, $\mathrm{CH}_{2}$ ), 1.02 (s, H, $\mathrm{CH}_{2}$ ), 1.68 (s, $\left.\mathrm{H}, \mathrm{CH}_{2}\right), 2.13\left(\mathrm{~s}, 2 \mathrm{H}, \mathrm{CH}_{2}\right), 2.76\left(\mathrm{~m}, \mathrm{H}, \mathrm{CH}_{3}\right), 7.23(\mathrm{~s}, \mathrm{H}$, Ph-H), 7.86 (m, H, Ph-H), 7.90 (m, H, Ph-H), 8.01 (m, H, Ph-H), 8.09 (m, H, Ph-H), 8.42 (s, H, Ph-H), 8.59 (d, H, J $2.7 \mathrm{~Hz}, \mathrm{Ph}-\mathrm{H}), 11.04$ (s, H, NH).

Preparation of electrospinning precursor solution and film

PANADC (1.00 g) was dissolved in DMF (4.0 g) solution to prepare precursor solution with a concentration of $20 \mathrm{wt} . \%$. The solution was rapidly stirred for $24 \mathrm{~h}$ at room temperature. The resulting clear homogenous solution was used for fabricating the nanofibrous film. A syringe with an inserted wire to connect the high-voltage supply was filled with the precursor solution. An aluminum foil served as a receiver. The distance between syringe and receiver was $15 \mathrm{~cm}$. The high-voltage supply was fixed at $16 \mathrm{kV}$. The spinning rate was controlled at about $4 \mathrm{~mL} \mathrm{~h}^{-1}$ by the microinfusion pump. Electrospinning was performed at room temperature. After the electrospinning process, the generated nanofibrous film was removed from the receiver with tweezers.

\section{Results and Discussion}

Fourier transform infrared (FTIR) investigations of PANADC film

FTIR was utilized to confirm that the recognition group was successfully grafted onto PANADC. Figures 1a and $1 \mathrm{~b}$ displayed the FTIR spectra of PANAD and PANADC, respectively. The bending vibrations at $739 \mathrm{~cm}^{-1}$ testified the pyridine group in PANAD and PANADC, meanwhile the stretching vibration at $1242 \mathrm{~cm}^{-1}$ in PANAD and $1250 \mathrm{~cm}^{-1}$ in PANADC were also ascribed to pyridine group. The characteristic bands around $980 \mathrm{~cm}^{-1}$ represented the $\mathrm{C}-\mathrm{H}$ in PANAD and PANADC. Moreover, the characteristic bands of PANAD at $1375 \mathrm{~cm}^{-1}$ and the bands of PANADC at $1377 \mathrm{~cm}^{-1}$ proved the existence of $\mathrm{C}=\mathrm{O}$, and the bands exhibited at $2862 \mathrm{~cm}^{-1}$ in PANAD and at $2865 \mathrm{~cm}^{-1}$ in PANADC represented the stretching vibration of $\mathrm{Ar}-\mathrm{H}$. In addition, the band at $2226 \mathrm{~cm}^{-1}$ in PANAD and the band at $2228 \mathrm{~cm}^{-1}$ in PANADC were ascribed to cyanogroup. The characteristic bands displayed at $1659 \mathrm{~cm}^{-1}$ in both PANAD and PANADC confirmed that imine were successfully introduced into PANAD and PANADC, this phenomenon indicated that 2,6-diaminopyridine and PANA generated - NH- structure in the PANAD, and the larger peak width indicated that there was a large amount of grafting. Compared with Figure 1a, Figure 1b exhibited an obvious band at $1722 \mathrm{~cm}^{-1}$, which was assigned to coumarin lactone ring, so we considered that coumarin group was introduced in PANADC. 


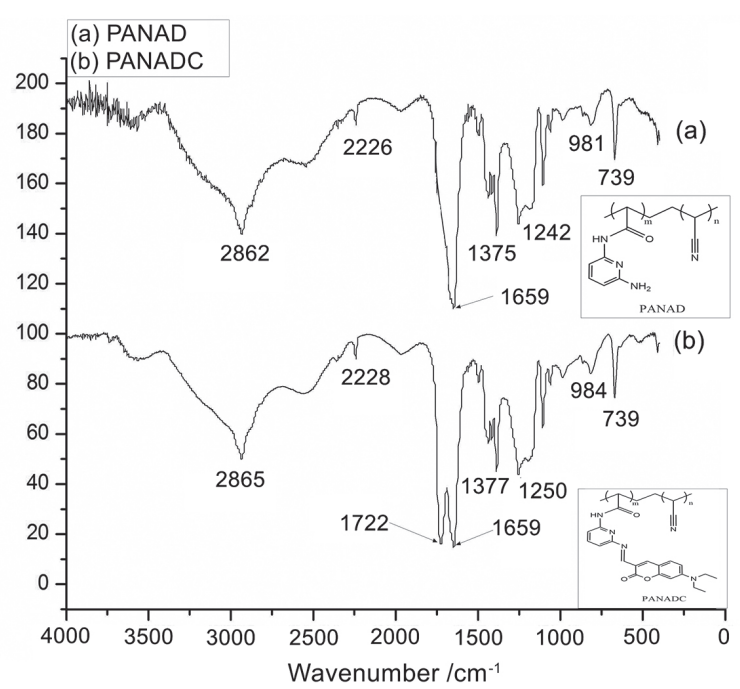

Figure 1. FTIR spectra of (a) PANAD and (b) PANADC.

\section{Morphologies of PANADC}

Figure 2 shows the typical scanning electron microscopy (SEM) images of the PANADC nanofibrous film under 10 and $2 \mu \mathrm{m}$. It depicted that PANADC film was composed of numerous, randomly oriented nanofibers, and there were no obvious serious cracks or degradation in the surface of PANADC nano-fiber under the preparation conditions. The average nanofiber diameter (D) can be estimated based on the following equation. ${ }^{13}$

$\mathrm{D}=\frac{1}{\mathrm{n}} \sum_{\mathrm{i}=1}^{\mathrm{n}} \mathrm{X}_{\mathrm{i}}^{*} \frac{\mathrm{B}}{\mathrm{L}}$

where $\mathrm{n}$ stands for the number of nanofibers in the SEM images, $\mathrm{X}$ stands for the diameter of each nanofiber, B is the scale bar, and L refers to the length of the scale bar. So the average diameter of PANADC nanofiber is about $0.97 \mu \mathrm{m}$ on the basis of Figure $2 \mathrm{~b}$. In summary, PANADC nanofibrous provides a valuable network structure with high specific surface area, and this unique porous structure could evidently promote the external analyte to approach the recognition group on the surface of nano-fiber and also greatly accelerate the detection efficiency. ${ }^{14}$

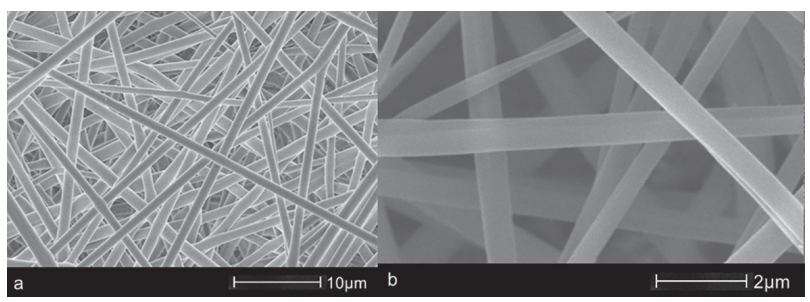

Figure 2. SEM image of PANADC nanofibers under different scales: (a) $10 \mu \mathrm{m}$ and (b) $2 \mu \mathrm{m}$.
Response of poly PANADC nanofibrous film to $\mathrm{Fe}^{3+}$ ions

The sensitivity of PANADC nanofibrous film toward $\mathrm{Fe}^{3+}$ was investigated by titration experiments. The titration experiments were implemented in acetonitrile $\left(\mathrm{CH}_{3} \mathrm{CN}\right)$ and $N$-[2-hydroxyethyl]piperazine- $N$ '-[2-ethanesulfonic acid]-sodium hydroxide (HEPES-NaOH) buffer solution at $\mathrm{pH} 7.1\left(\mathrm{CH}_{3} \mathrm{CN}: \mathrm{H}_{2} \mathrm{O}=1: 1, \mathrm{v} / \mathrm{v}\right)$. As illustrated in Figure 3, PANADC exhibited an absorption maximum at $416 \mathrm{~nm}$ in the UV absorption spectrum. Upon the addition of $\mathrm{Fe}^{3+}$, the absorption band had some degree of change, so $416 \mathrm{~nm}$ was utilized as excitation wavelength in fluorescence titration experiment. The PANADC nanofibrous film emit fluorescence at $467 \mathrm{~nm}$ in fluorescent emission spectra (excited at $416 \mathrm{~nm}$ ). When $\mathrm{Fe}^{3+}$ was introduced in the testing system, as illustrated in Figure 4, the fluorescence intensity of PANADC nanofibrous film obviously decreased. In addition, Figure 5 depicted that the relation between the decreasing fluorescence intensity of the nanofibrous film and the concentration of $\mathrm{Fe}^{3+}$ was in a linear manner $\left(R^{2}=0.99375\right)$, and the detecting limit could be reckoned from the linear relationship. The limit of detection (LOD) was calculated to be $1.063 \times 10^{-5} \mathrm{~mol} \mathrm{~L}^{-1}$ based on $\mathrm{LOD}$ equation $\left(\mathrm{LOD}=\mathrm{KSb}_{1} / \mathrm{S}\right.$, where $\mathrm{K}=3$; $\mathrm{Sb}_{1}$ is the standard deviation of the blank solution; $\mathrm{S}$ is the slope of the calibration curve). ${ }^{15}$ Moreover, the outstanding linear relationship proved that PANADC nanofibrous film had potential application for quantitative detection of $\mathrm{Fe}^{3+}$.

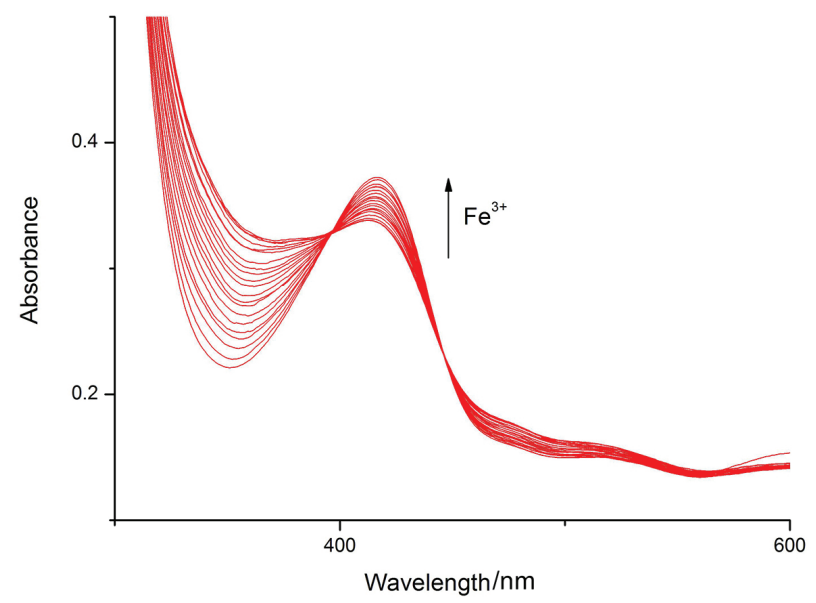

Figure 3. Absorption spectra of PANADC in $\mathrm{CH}_{3} \mathrm{CN}-\mathrm{H}_{2} \mathrm{O}$ solution.

The effect of $\mathrm{pH}$

The effect of operational $\mathrm{pH}$ is one of the most influential factors for fluorescent sensor in detecting metal ions. The fluorescence intensities of PANADC nanofibrous film and PANADC with $\mathrm{Fe}^{3+}$ in different $\mathrm{pH}$ values were shown in Figure 6. We could find that the $\mathrm{pH}$ values have 
certain influence on both PANADC nanofibrous film and PANADC with $\mathrm{Fe}^{3+}$ under the condition of strong acid

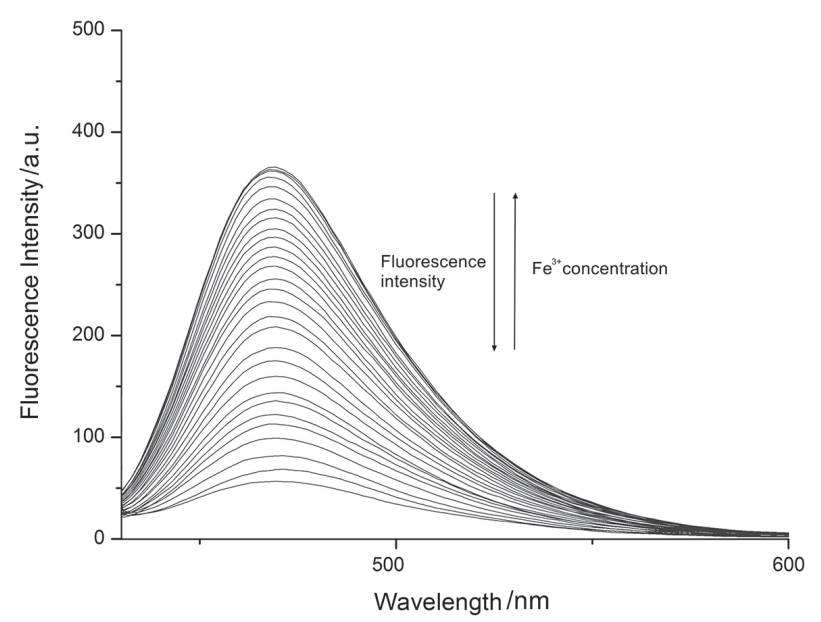

Figure 4. Fluorescent emission spectra of PANADC nanofibrous film in different $\mathrm{Fe}^{3+}$ concentrations in $\mathrm{CH}_{3} \mathrm{CN}-\mathrm{H}_{2} \mathrm{O}$ solution.

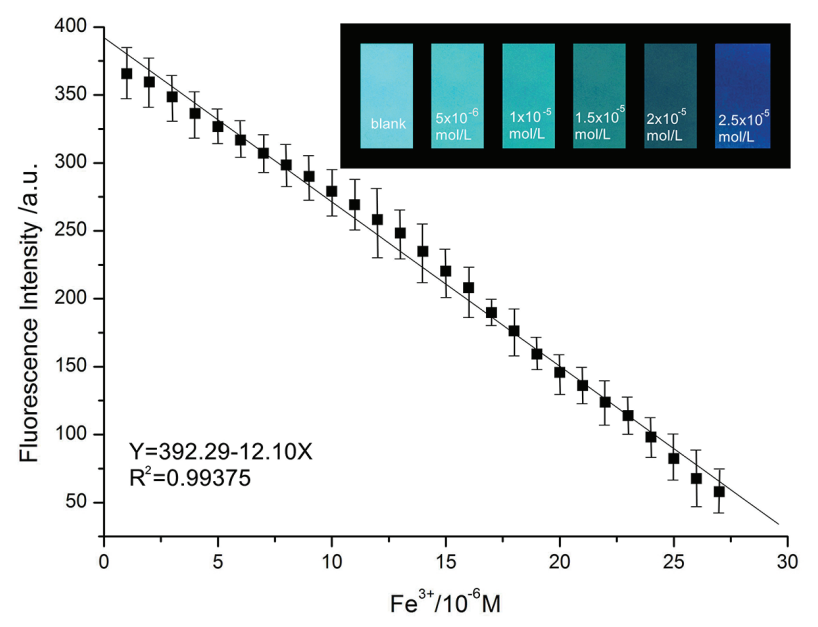

Figure 5. Response of flourescent signal in different $\mathrm{Fe}^{3+}$ concentrations.

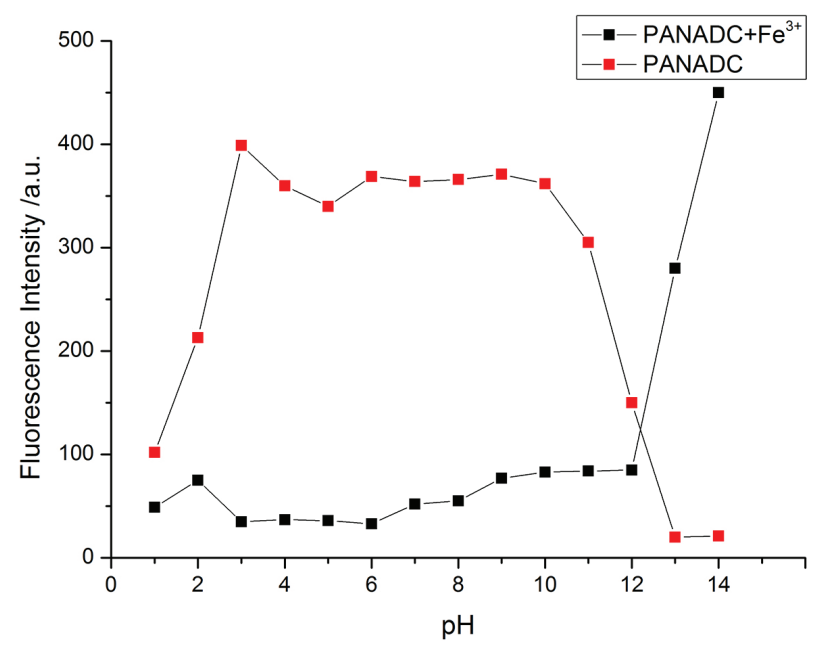

Figure 6. Fluorescence emission of PANADC nanofibrous film in $\left(\mathrm{CH}_{3} \mathrm{CN}-\mathrm{H}_{2} \mathrm{O}=1: 1, \mathrm{v} / \mathrm{v}\right)$ solution at different $\mathrm{pH}$ values. and alkali, this phenomenon may be attributed to the intramolecular charge transfer of receptor in PANADC, but the fluorescence intensities were relatively stable in the condition of $\mathrm{pH} 3-10$, so we consider that PANADC nanofibrous film could maintain its sensitivity to $\mathrm{Fe}^{3+}$ in pH 3-10.

\section{Selective and competitive experiments}

To test the selectivity of PANADC nanofibrous film towards $\mathrm{Fe}^{3+}$, selective and competitive experiments were conducted in $\mathrm{CH}_{3} \mathrm{CN}$ and HEPES-NaOH buffer solution at $\mathrm{pH} 7.1\left(\mathrm{CH}_{3} \mathrm{CN}: \mathrm{H}_{2} \mathrm{O}=1: 1, \mathrm{v} / \mathrm{v}\right)$. Some common metal ions in the environment such as $\mathrm{K}^{+}, \mathrm{Cu}^{2+}, \mathrm{Co}^{2+}, \mathrm{Ni}^{2+}, \mathrm{Ca}^{2+}$, $\mathrm{Mg}^{2+}, \mathrm{Mn}^{2+}, \mathrm{Cd}^{2+}, \mathrm{Pb}^{2+}, \mathrm{Fe}^{2+}, \mathrm{Hg}^{2+}, \mathrm{Cr}^{3+}, \mathrm{Al}^{3+}$ and $\mathrm{Fe}^{3+}$ were introduced to examine their influence on the fluorescence response of PANADC nanofibrous film. As illustrated in Figure 7, black bar represented selective experiments and red bar represented competitive experiments. In selectivity experiments, $100 \mu \mathrm{mol} \mathrm{L} \mathrm{L}^{-1}$ of $\mathrm{K}^{+}, \mathrm{Cu}^{2+}, \mathrm{Co}^{2+}$, $\mathrm{Ni}^{2+}, \mathrm{Fe}^{2+}, \mathrm{Ca}^{2+}, \mathrm{Mg}^{2+}, \mathrm{Mn}^{2+}, \mathrm{Cd}^{2+}, \mathrm{Pb}^{2+}, \mathrm{Hg}^{2+}, \mathrm{Cr}^{3+}, \mathrm{Al}^{3+}$ and $\mathrm{Fe}^{3+}$ were taken into PANADC in $\mathrm{CH}_{3} \mathrm{CN}$ and buffer solution, only $\mathrm{Fe}^{3+}$ caused fluorescence quenching at $467 \mathrm{~nm}$ in the emission spectra, the introduction of other metal ions slightly affected the fluorescence at $467 \mathrm{~nm}$. Furthermore, competition experiments were performed to further test the interference of other metal ions in the detecting $\mathrm{Fe}^{3+}$, PANADC nanofibrous film were the first to induce fluorescence quenching by $100 \mu \mathrm{mol} \mathrm{L} \mathrm{L}^{-1}$ of $\mathrm{Fe}^{3+}$ before mixed $1 \mathrm{mmol} \mathrm{L}{ }^{-1}$ of $\mathrm{K}^{+}, \mathrm{Cu}^{2+}, \mathrm{Co}^{2+}, \mathrm{Ni}^{2+}, \mathrm{Ca}^{2+}$, $\mathrm{Fe}^{2+}, \mathrm{Mg}^{2+}, \mathrm{Mn}^{2+}, \mathrm{Cd}^{2+}, \mathrm{Pb}^{2+}, \mathrm{Hg}^{2+}, \mathrm{Cr}^{3+}, \mathrm{Al}^{3+}$ each, and all of the fluorescence intensity of PANADC nanofibrous film at $467 \mathrm{~nm}$ exhibited still quenching. So it was clearly indicated that these ions did not interfere with the detection of $\mathrm{Fe}^{3+}$. Therefore the above experiments had proven that

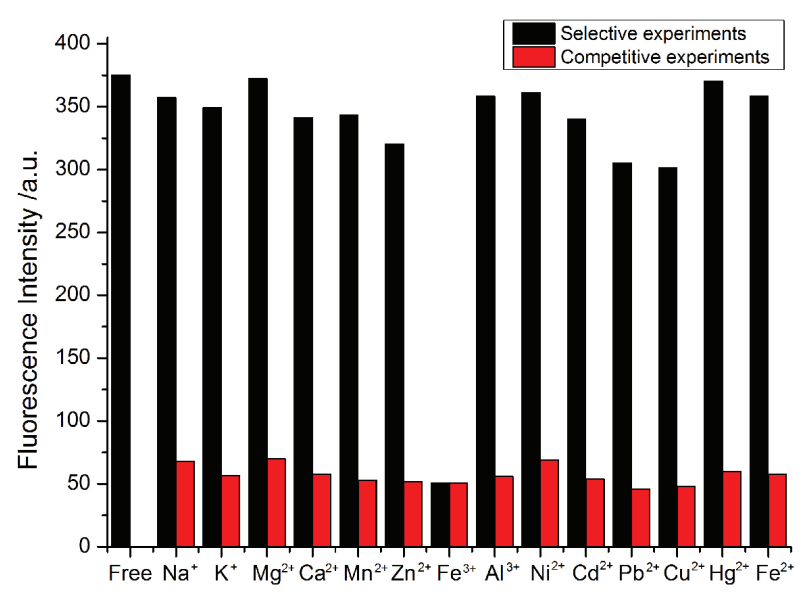

Figure 7. Selective experiments (black bar) and competitive experiments (red bar) of PANADC nanofibrous film. 
PANADC nanofibrous film is an functional fluorescent sensor in detecting $\mathrm{Fe}^{3+}$.

For rationalizing the observed fluorescence quenching of PANADC nanofibrous film in detecting $\mathrm{Fe}^{3+}$, we may consider that the strong fluorescence intensity of PANADC nanofibrous film is attributed to the coumarin fluorophore. In the absence of $\mathrm{Fe}^{3+}$, the excited electrons in coumarin fluorophore directly transit to the ground state to emit fluorescence. After adding $\mathrm{Fe}^{3+}$, the coordinates of $\mathrm{Fe}^{3+}$ and acceptor moiety will block the electron transit from the electrondonating $\mathrm{C}=\mathrm{N}$ moiety to the coumarin ring, and restrain the fluorescence emission of coumarin fluorophore, which result in a substantial decrease in fluorescence intensity. For other metal ions, their presences will not inhibit the electron transfer in the system, so this phenomenon results in a good selectivity of the PANADC nanofibrous film to $\mathrm{Fe}^{3+}$.

\section{Adsorption kinetics of $\mathrm{Fe}^{3+}$ onto PANADC nanofibrous film}

At present most fluorescence sensors are used for detecting analytes, but not as adsorbents from solution. The innovation of PANADC nanofibrous film is that the prepared nanofibrous film is not only a sensor for $\mathrm{Fe}^{3+}$, but also an efficient adsorbent for $\mathrm{Fe}^{3+}$. The equilibrium adsorption amounts and Langmuir adsorption curve were investigated in Figure 8. The PANADC nanofibrous film was cut into the shape of $1.0 \times 2.5 \mathrm{~cm}$, and added to aqueous solution in different concentrations of $\mathrm{Fe}^{3+}$ for $24 \mathrm{~h}^{16}$ The concentration of $\mathrm{Fe}^{3+}$ ions left in aqueous solution was measured by inductively coupled plasma mass spectrometry (ICP-MS). The equilibrium adsorption amounts in different equilibrium concentrations were illustrated in Figure 8a. It was found that the adsorption of $\mathrm{Fe}^{3+}$ increased sharply with the increase in concentration until the $\mathrm{Fe}^{3+}$ reach $100 \mathrm{mg} \mathrm{L}^{-1}$, then the adsorption amounts tend to stabilize. The reason why the adsorption curve leveled off might be

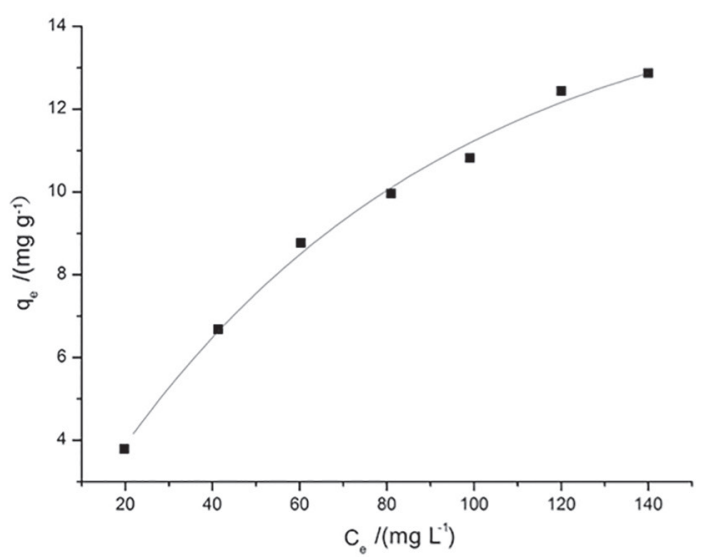

due to the chelating sites for $\mathrm{Fe}^{3+}$ on the surface of PANADC becoming saturated, and excess $\mathrm{Fe}^{3+}$ cannot be adsorbed. ${ }^{17}$ After that, the experimental adsorption equilibrium data of $\mathrm{Fe}^{3+}$ was analyzed according to the Langmuir adsorption equation, which is given as follows: ${ }^{18}$

$$
\frac{\mathrm{C}_{\mathrm{e}}}{\mathrm{q}_{\mathrm{e}}}=\frac{1}{\mathrm{~K}_{\mathrm{L}} \mathrm{q}_{\mathrm{m}}}+\frac{\mathrm{C}_{\mathrm{e}}}{\mathrm{q}_{\mathrm{m}}}
$$

where $q_{e}$ is the equilibrium quantity of the metals ions adsorbed onto the PANADC nanofibrous film $\left(\mathrm{mg} \mathrm{g}^{-1}\right)$, $\mathrm{C}_{\mathrm{e}}$ is the equilibrium concentration $\left(\mathrm{mg} \mathrm{L}^{-1}\right)$, and $\mathrm{q}_{\mathrm{m}}\left(\mathrm{mg} \mathrm{g}^{-1}\right), \mathrm{K}_{\mathrm{L}}\left(\mathrm{L} \mathrm{mg}^{-1}\right)$ are the Langmuir constants related to the saturation adsorption capacity and binding energy (affinity), respectively. ${ }^{19}$ As shown in Figure 8b, the relationship between $\mathrm{C}_{\mathrm{e}} \mathrm{q}_{\mathrm{e}}{ }^{-1}$ and $\mathrm{C}_{\mathrm{e}}$ was of linearity $\left(R^{2}>0.98\right)$. Based on the Langmuir theory, each reaction location absorbed $\mathrm{Fe}^{3+}$ solely in this nanofibrous film. Thus, monolayer adsorption occurred on the poly PANADC nanofibrous film. ${ }^{20}$ Therefore, we could calculate from the slope and intercept of the $\mathrm{C}_{\mathrm{e}} \mathrm{q}_{\mathrm{e}}^{-1}$ versus $\mathrm{C}_{\mathrm{e}}$ plot in Figure $8 \mathrm{~b}$. The adsorption capacity was calculated to be $13.93 \mathrm{mg}$ of $\mathrm{Fe}^{3+}$ ions per gram of PANADC film (Table 1).

Table 1. The Langmuir constants for $\mathrm{Fe}^{3+}$ on PANADC nanofibrous film

\begin{tabular}{lccc}
\hline Metal ion & $\mathrm{K}_{\mathrm{L}} /\left(\mathrm{L} \mathrm{mg}^{-1}\right)$ & $\mathrm{q}_{\mathrm{m}} /\left(\mathrm{mg} \mathrm{g}^{-1}\right)$ & $\mathrm{R}^{2}$ \\
\hline $\mathrm{Fe}^{3+}$ & 5.209 & 13.93 & 0.988
\end{tabular}

$\mathrm{K}_{\mathrm{L}}$ : Langmuir constant related to the binding energy (affinity); $\mathrm{q}_{\mathrm{m}}$ : Langmuir constat related to the saturation adsorption capacity; $\mathrm{R}^{2}$ : linearity.

\section{Conclusions}

A novel fluorescent nanofibrous film for sensing and adsorbing $\mathrm{Fe}^{3+}$ was successfully developed, the nanofibrous

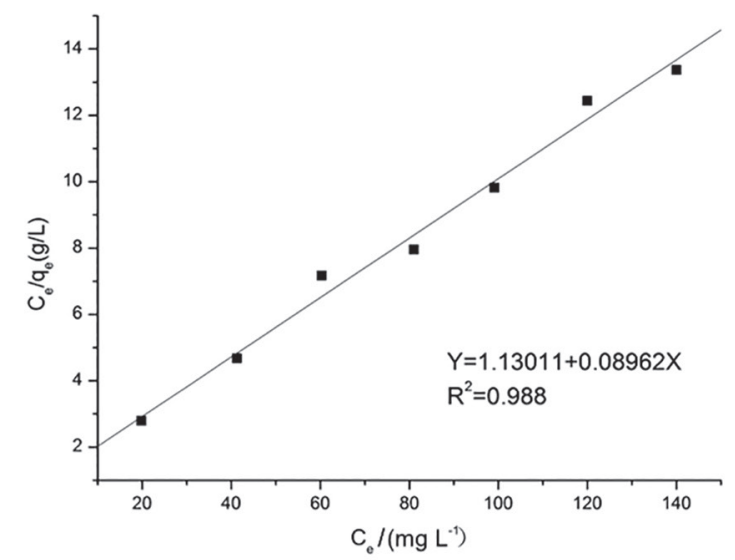

Figure 8. (a) Adsorption isotherm and (b) Langmuir plot of $\mathrm{Fe}^{3+}$ on the PANADC nanofibrous film. 
film not only possessed good selectivity and sensitivity for $\mathrm{Fe}^{3+}$, but also achieved adsorption for $\mathrm{Fe}^{3+}$. We expect that such $\mathrm{Fe}^{3+}$ nanofibrous film sensor will have application value in environmental detection.

\section{Supplementary Information}

Supplementary information is available free of charge at http://jbcs.sbq.org.br as a PDF file.

\section{Acknowledgments}

The authors gratefully acknowledge the support of the Youth Science Foundation of Changchun University of Science and Technology (XQNJJ-2016-11) and the Natural Science Foundation of Inner Mongolia (No. 2015BS0202).

\section{References}

1. Dong, L.; Wu, C.; Zeng, X.; Mu, L.; Xue, S. F.; Tao, Z.; Zhang, J. X.; Sens. Actuators, B 2010, 145, 433.

2. Barman, A.; Hamelberg, D.; ACS Omega 2016, 1, 837.

3. Mabrouk, M.; Savoyant, A.; Giovanelli, L.; Clair, S.; Hayn, R.; Chaabane, R.; J. Phys. Chem. C 2017, 121, 4253.

4. Markevich, A.; Baldoni, M.; Warner, J.; Kirkland, A.; Besley, E.; J. Phys. Chem. C 2016, 120, 21998.

5. Yang, Y.; Li, X.; Shen, L.; Wang, X.; Hsiao, B.; Ind. Eng. Chem. Res. 2017, 56, 3077.

6. Wang, Z.; Ma, Q.; Dong, X.; Li, D.; Xi, X.; Yu, W.; Wang, J.; Liu, G.; ACS Appl. Mater. Interfaces 2016, 8, 26226.
7. Sun, L.; Yu, X.; Sun, M. D.; Wang, H. G.; Xu, S. F.; Dixon, J. D.; Wang, Y. A.; Li, Y. X.; Yang, Q. B.; Xu, X. Y.; J. Colloid Interface Sci. 2011, 358, 73.

8. Kong, N.; Lin, F.; Zhao, W.; Lombardi, J.; Almihdhar, M.; Liu, K.; Yan, S.; Kim, J.; Luo, J.; Hsiao, B.; Poliks, M.; Zhong, C.; ACS Sens. 2016, 1, 1060.

9. Si, Y.; Li, J.; Zhao, C.; Deng, Y.; Ma, Y.; Wang, D.; Sun, G.; ACS Biomater. Sci. Eng. 2017, 3, 854.

10. Fan, J.; Chang, X.; He, M.; Shang, C.; Wang, G.; Yin, S.; Peng, H.; Fang, Y.; ACS Appl. Mater. Interfaces 2016, 8, 18584.

11. Wang, W.; Li, Y. P.; Sun, M. D.; Zhou, C.; Zhang, Y.; Li, Y. X.; Yang, Q. B.; Chem. Commun. 2012, 48, 6040.

12. Lin, W. J.; Yuan, L.; Feng, J. B.; Cao, X. W.; Eur. J. Org. Chem. 2008, 16, 2689.

13. Wang, W.; Yang, Q. B.; Sun, L.; Wang, H. G.; Zhang, C. Q.; Fei, X. L.; J. Hazard. Mater. 2011, 194, 185.

14. Wang, W.; Wang, X. L.; Yang, Q. B.; Fei, X. L.; Sun, M. D.; Song, Y.; Chem. Commun. 2013, 49, 4833.

15. Zhou, C.; Song, Y.; Li, Y. P.; RSC Adv. 2014, 4, 33614.

16. Haider, S.; Park, S. Y.; J. Membr. Sci. 2009, 328, 90.

17. Ramazan, C.; Cengiz, S.; Mehmet, S.; Sep. Purif. Technol. 2006, 49, 107.

18. Saeed, K.; Haider, S.; Oh, T. J.; Park, S. Y.; J. Membr. Sci. 2008, 322,400

19. Deng, S.; Bai, R.; J. Colloid Interface Sci. 2003, 260, 265.

20. He, Z. Y.; Nie, H. L.; White, C. B.; Bioresour. Technol. 2008, 99, 7954.

Submitted: June 16, 2017

Published online: September 1, 2017 